\title{
Design recommendations for the creation of icons for the elderly
}

\author{
Alexander Mertens*, Christopher Brandl, Philipp Przybysz, David Koch-Körfges \\ and Christopher M. Schlick \\ Chair and Institute of Industrial Engineering and Ergonomics of RWTH Aachen University, \\ Bergdriesch 27, 52062 Aachen, Germany
}

\begin{abstract}
During employment of icons in order to represent system functions, specific user requirements from elderly people have not been scientifically gathered and thus will merely be considered during the process of system design. The survey, with explicit consideration of technology acceptance and experience of 120 elderly probands, looked into the comprehension of four different classes of non-animated graphical representations. It was shown that among elderly, the use of photos compared to pictograms or clip art leads to a significantly higher recognition rate. The mapping of actions rather than objects leads to a further reduction of the error probability and is thus, especially in the context of telemedicine, preferable for the target group.
\end{abstract}

Keywords: Icons, human-computer interaction, elderly, user study, usability

\section{Motivation}

The efficiency, effectiveness and user satisfaction when interacting with IT systems is primarily dependant on the design of the user interface and consideration of the specific requirements of the target group [1]. Demographic change requires new approaches, as the significantly risen possibility of disease at a higher age and occurring multimorbidity [2] arise new scenarios for deployment within the IT based assistance of telemedical supply. Special requirements exist for the ergonomic interaction of elderly people with computers. In addition to the frequent lack of experience in handling electronic devices also physical constraints such as for example visual impairment, slowing of reaction time or motor deficits must be compensated. Important for the acceptance of technical assistance systems by the elderly er users are therefore a more intuitive handling of the functionalities, adequate visualization and direct feedback, which makes the whole interaction process more transparent to the user and thus allows a subjective impression of control over the operations. The design of the user interface plays a crucial role, as this is perceived by many users as "the system" [3]. Image and voice characters in the form of icons provide an information representation which is independent of the user's language skills and can be found even at low resolution and small display applications. The divergent understanding of icons as well as the different meaning of language signs for users from different cultures, regions and language areas in times of globalization and the Internet, is a well known and well-studied problem [4]. What differences exist, regarding the intuitive understanding of symbols for different age groups, or which adaptation is necessary in order to make visualizations easier to understand, has not yet been studied in a final manner.

The aim of this study is to evaluate what kind of non-animated graphical information enables elderly users the most intuitive interaction and offsetting typical age effects. Among a very high detection rate, the author's ambition is mainly to minimize input errors by incorrectly interpreted meanings, since this defines the robustness of the system operations decisively in emergency situations. For this purpose, 14 typical application scenarios of telemedical monitoring were identified [5], which were assigned by the elderly probands to corresponding system functions using different symbol classes (see Fig. 1).

\footnotetext{
*Corresponding author. E-mail: a.mertens@iaw.rwth-aachen.de
} 

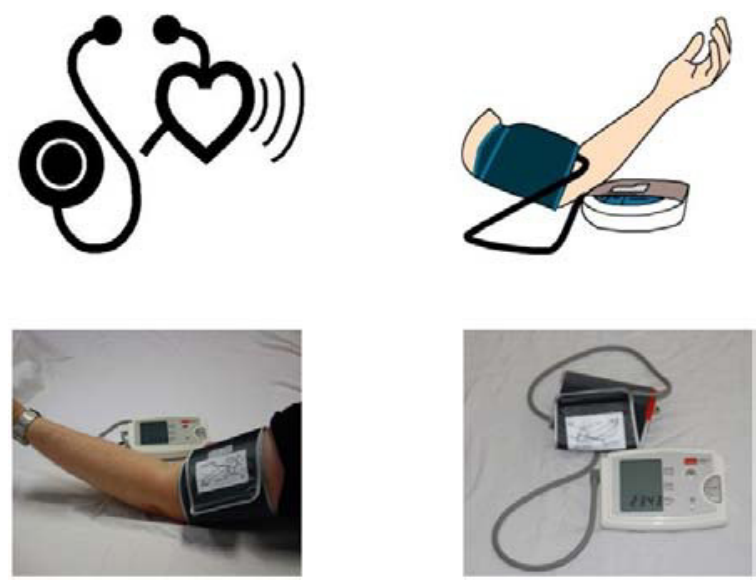

Figure 1: Exemplarily icons of each symbol class for the scenario of the blood pressure / heart rate (from left to right): pictogram, clip art, photo (action), photo (object)

\section{State of Research}

The term icon refers to small picture like symbols that are used in computers and technical equipment, replacing words on the program interface. They represent specific capabilities of the system and can be activated by the user to enable access to functionality. Here, a well-formatted, graphical display increases the productivity and safety at work, especially with inexperienced or anxious people [6]. The advantages in using icons for human-computer communication, which were described in the literature, are:

- Icons can easily be recognized and remembered [7]

- Users prefer icons to text on problem solving, although their efficiency rate is equal to or less than in purely textual user interfaces [8]

- Pictures provide a universal recognition, as fewer hurdles exist than with the use of colloquial terms $[9,10]$

- Icons provide user references / calls to action (affordance) which enable an intuitive and natural use of IT systems $[9,11]$

To make the obvious benefits of icons available, numerous factors in the selection and orchestration and the experience and knowledge of the user are decisive. Inappropriate pictures or unknown symbols, which do not correspond to their own culture, lead the user to incomprehensible systems and make it more difficult to allocate desired functions [12] Symbolic images facilitate the transparency for the user, which may not be achieved in plain text (or acronyms) in a similar way [13]. Here, the use of icons was not meant to be a substitution, but rather a supplement [14]. Guastello showed in a study that this combination of different modalities allows an optimal information transfer [15].

Especially for the symbolization of actions (verbs) strong age effects with understanding and processing speed occur. Experience with the stereotypes here is the most influential factor when dealing with the contextual interpretation of the meaning [16]. The use of indirect symbols as $\boldsymbol{\vee}$ representing a ,want" reduces the recognition quota independently from the decision to use static or animated graphics [17].

The basic use of information graphics as a mean to counteract deficiencies of the visual system of the elderly and compensate for lack of experience with IT-based systems have been evaluated in numerous studies [18]. Thus, Arnott et al. [19] have modified email programs in such a way that larger buttons and fonts were used, the icons were provided with an explanatory word and no further introduction of new symbols and metaphors between the processes was needed. It was found, compared to unchanged systems, a significant positive impact on the effectiveness and in particular to the satisfaction of the elderly users took place.

The use of icons in the menu design of small displays (e.g. mobile phones) and their positive effect on handling for elderly users with regard to concreteness and complexity on semantic transparency was also demonstrated [20,21]. Kim and Lee found out that for younger mobile phone users, the cultural background plays a crucial role in the interpretation of different levels of abstraction and if the subjects have a clear preference for symbols which they already knew from other contexts and situations [22]. The distance between symbols following Lindberg et al [23] does not affect the search time by users. The symbol size is a decisive time factor when finding specific icons, a visual angle of less than $0.7^{\circ}$ leads to a significantly higher amount of time.

\section{Methodology}

\subsection{Participants}

A total of 120 probands (48 male, 72 female) participated in the user study. The participants were partitioned in five age groups: under 50 years $(n=23)$, 
51-60 years $(\mathrm{n}=26), 61-70$ years $(\mathrm{n}=19), 71-80$ years $(n=29)$ and $81-95$ years $(n=23)$. Most of the participants were recruited in the University Hospital Aachen; the acquisition of other participants was accomplished in nursing homes, senior homes and outpatient facilities such as sports groups and cardiac care services. With regard to health status, the participants reported to suffer, on average, from 3.7 of 14 $(\mathrm{SD}=1.9)$ mentioned age-related symptoms.

The cognitive capacity for self-reliant processing of the task and the questionnaire was considered feasible for all subjects, so the results are transferable to unaffiliated interaction with equally designed telemedical systems. The social background of the participants was mixed and thus provides representative indicators for the target group (see Fig. 2).

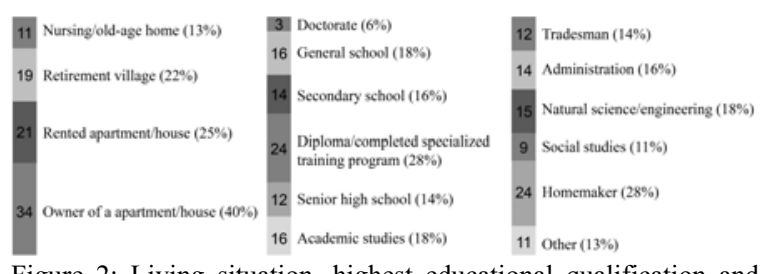

Figure 2: Living situation, highest educational qualification and working range of participants

\subsection{Pretests and Inclusion Criteria for Participation}

\subsubsection{Acceptance of Technology}

The acceptance of technology as an independent variable influencing the performance of humancomputer interaction is determined a priori and thus enables a differentiated analysis of the results. Based on the works of Beier [24] the attitudes of the elderly participants were evaluated with 15 strictly positive formulated statements that had to be rated according to a 4-point Likert Scale. These results represent the general attitudes for the seven ascertained dimensions (comfort, interest, efficacy, control, dehumanization, gender equality and value in use).

\subsubsection{Computer Literacy}

In order to measure computer literacy and evaluate the correlation with the test results a questionnaire from Sengpiel et al. [25] with nineteen items was used. The survey is based on the symbol and term knowledge gained during human-computer interaction and is generally seen as an indicator towards a person's competence in handling a computer system. Experiences such as duration, frequency and quality of usage and availability of a computer are asked in general demographic section.

\subsubsection{Near vision and color perception}

The central visual acuity describes the ability of the eye, to differentiate two closely spaced points from each other. Full visual acuity is achieved at a visual acuity of 1.0 or 100 percent. To participate in the study, the participants need a visual acuity - with the appropriate visual aid - of at least 0.75 . Relevant is here the so-called near vision, which corresponds to a distance of about 30-40 centimeters and for example is needed to read. To study the visual acuity eye charts modified according to Snellen index were used. The probands had in each line a black number between four black letters on white background. They had to identify it and write it down. Crucial for determination of the near vision is line with the smallest font size in which the number was still detected correctly [26].

As a color vision deficiency (Dyschromatopsie) has different effects on performance of the various symbol classes and thus plays an unquantifiable effect on the results, only test persons were included with accurate color perception in the study. The color vision test was carried out using a simple qualitative method, in which the participants were shown four pseudoisochromatic color plates [27]. They were then asked to read one and two digit numbers displayed on the plates.

\subsection{Study Implementation and Setup}

For the above tests, a related questionnaire was created that has been extended to mapping functions between symbols and typical use cases when interacting with telemedical monitoring systems (see Table 3 ). From 64 Icons (16 per symbol class) 16 were chosen randomly for each questionnaire and also arranged in a random sequence.

Professional input from all relevant sources, including doctors, medical technicians, designers, nursing staff, information scientists and ergonomists was accumulated in order to gain a thorough knowledge on the design of icons for all categories. This was done in a workshop containing all personalities from the previously mentioned sources. The photos were either shot by the authors themselves or bought from a professional photo studio. The authors tried to create a consistent quality of expressiveness and recognizability of the designed icons. The aim of this work was explicitly not the evaluation of the used 
icons but rather the evaluation of different classes of non animated symbols. Thus, no case specific icons were used respectively icons that allow a universal semantic comprehension (e.g. "?"). This results in a reduced bias throughout the data collection, which may have been caused through previous knowledge as well as individual experience.

The icons were placed in $3 \times 3 \mathrm{~cm}$ large, equally spaced areas, to cover a similar displaying area, keeping the size independent from the symbol properties. The possible answers for the tasks were constant in all questionnaires, with two answers and two symbols having no appropriate correlation, thus serving as control issues making possible contradictions visible. The questionnaires were handed out in different places, with an indication that there are no entry requirements in the form of technical training, possession of a computer, or experience in computer operation.

\section{Results}

\subsection{Reliability}

The reliability of the used measurement instruments was identified retrospectively on the basis of internal consistency (Cronbach's coefficient alpha). As the tests used to determine the computer literacy and the design of pictorial items used dichotomous items, Kudar Richardson formula 20 was used to determine reliability. For the questionnaire on technology acceptance, the analysis showed a Cronbach's alpha of 0.88 , the test on visual signs showed a similar value of 0.86 . The test for computer literacy gave a value of 0.92 . Overall, the used scales and obtained data showed a generally high reliability.

\subsection{Acceptance of Technology}

The mean values and standard deviations on technology acceptance are shown in Fig. 3 for various subgroups. Over the entire sample the low interest $(\mathrm{M}=$ $2.13 \mathrm{SD}=0.9)$ and the fear of losing control $(\mathrm{M}=$ $1.97, \mathrm{SD}=0.91)$ are noticeable. A typical pattern in the sample was the extremely strong correlation between the dimensions of comfort and effectiveness ( $\mathrm{r}$ $=0.84, \mathrm{p}<0.001)$. Generally, there was a negative relationship between the seven dimensions of the questionnaire on technology acceptance and frequency of computer use and the fact that computers were used during the work. With an increase in computer use a similar high value in the dimension comfort occurred. A one-way ANOVA indicated that among the dimensions comfort, efficiency, control and value significant differences between the different age groups exist. A post-hoc analysis showed that the age group of 80 - to 95-year-olds is different on the four dimensions relative to the other groups, and on average they score more than one point less for each dimensions. This shows that people who are beyond their 80th year feel less comfortable and self-efficient in using computers and less appreciate the practical benefits of computer technology.

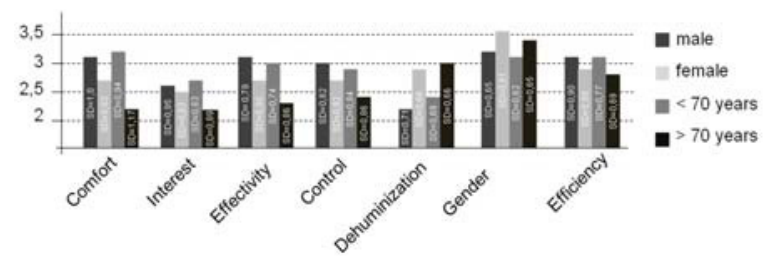

Figure 3: Attitude of the elderly towards Computers

Table 1

Correlation of the seven dimensions of attitudes towards computers

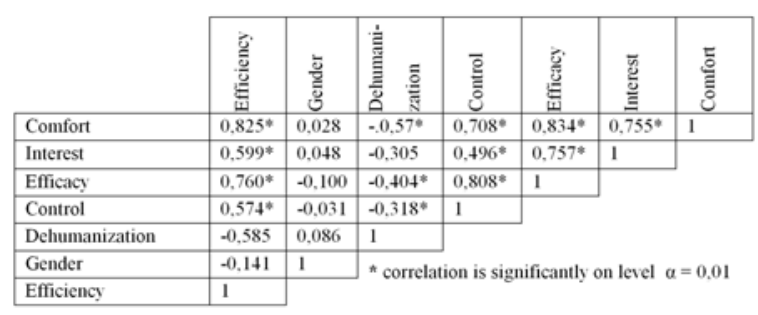

\section{Computer Literacy}

On average, the subjects had about 7 years $(\mathrm{SD}=$ 5.1) experience in using computers. The use was largely private ( $8 \%$ professional, $45 \%$ private, $47 \%$ in both commercial and free). $60 \%$ of respondents said they do not use a computer more frequently than three times a week. Within the age groups above 70 years average experience in handling computers strongly decreases and lies at 2,8 $(\mathrm{SD}=1.2)$ years, which is also reflected in the obtained data on computer literacy (see Tab. 2). Only 16\% of the questioned individuals above 70 have access to a computer at home, whereas in the group below 61 years almost every second has access. The evaluation of the experience with operation symbols and IT terminology showed that on average $60 \%$ of the 19 items were correctly assigned. Individuals from the age groups above 70 years almost always achieved lower scores than their references from younger age groups, which 
was expected from their access ratio both at home and at work.

Table 2

Average quotient of correct answers given while determining computer literacy of participants relative to age groups, educational standard and work fields in percentage.

\begin{tabular}{|l|c|c|c|c|c|c|}
\hline Age groups & $<50$ years & $51-60$ years & $61-70$ years & $71-80$ years & \multicolumn{2}{|c|}{$81-95$ years } \\
\hline \begin{tabular}{|l|c|c|c|c|c|}
\hline \\
Educational \\
standard
\end{tabular} & $\begin{array}{c}\text { General } \\
\text { school }\end{array}$ & $\begin{array}{c}\text { Secondary } \\
\text { school }\end{array}$ & $\begin{array}{c}\text { Diploma } \\
\text { Spec. Prog. }\end{array}$ & $\begin{array}{c}\text { Senior } \\
\text { highschool }\end{array}$ & $\begin{array}{c}\text { Acad. } \\
\text { studies }\end{array}$ & Prom. \\
\hline \multirow{2}{*}{ Work field } & 43.3 & 59.9 & 60.2 & 63.4 & 75.9 & 64.9 \\
\hline & Tradesmen & Admin. & Natural sc. & Homemaker & Social & Other \\
\cline { 2 - 8 } & 48.2 & 63.1 & 75.7 & 14.9 & 60.4 & 57.6 \\
\hline
\end{tabular}

4.4

$$
\text { Design of Visual Signs }
$$

The results from the tests on designing icons are depicted in Table 3. Overall it was shown that tested individuals were best able to assign system functions in a telemedical context with images of actions. Less successful was the assignment of photos representing objects alone, followed by pictograms and clip arts (see Figure 4). Due to the low probability of error for photos of actions they are particularly useful in critical situations and emergencies giving a robust shaping of the processes of human-computer interaction. It was proven, as expected, that arranging the use cases after decreasing overall hit rates shows that abstract functions have a generally lower reception.

It was shown that with elderly users, a purely symbolized representation of immaterial correlations is only partially useful. A chi-square test performed shows that the results are constant across the existing age groups and the distribution is not significantly $(\chi$ $\left.{ }^{2}=14.83, \mathrm{p}=0.79\right)$ different. The shown preference for photos is independent from the frequency of use $\left(\chi^{2}=15.2 ; p=0.51\right)$ as well as duration of use $\left(\chi^{2}=\right.$ $9.6 ; \mathrm{p}=0.65)$ which enables an ageing friendly approach.

\subsection{Inferential Statistics}

A descriptive analysis, of the quantitative data from chapters 4.2, 4.3 and 4.4, using appropriate probability measures, enables to draw a conclusion on stochastic dependencies and correlations for the examined sample. The determined results must not be postulated into any causal chain. However, specific probabilities for negative or positive dependencies may be determined. The results allow to transport the observations from the study to other user groups and operational areas, outside of the telemedical sector. A noticeable occurrence is the correlation between positive attitude towards computers and the overall high score on correctly assigned icons $(r=0.85$;
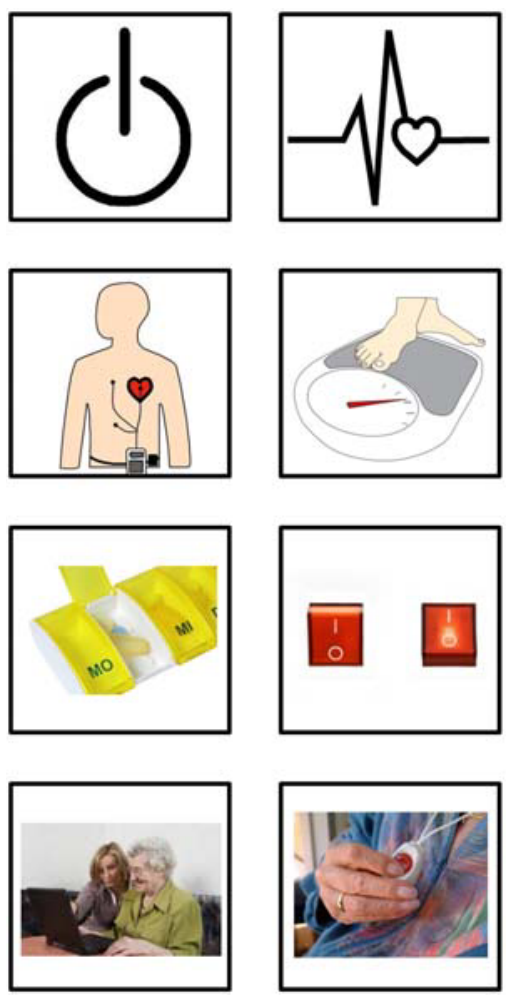

Figure 4: Exemplary icons used in the questionnaire representing the four symbol classes: pictogram, clipt art, photo of objects and photo of actions.

$\mathrm{p}<0.05)$. Only dehumanization and control see a reversed effect $(\mathrm{r}=-0.68 ; \mathrm{p}<0.13 ; \mathrm{r}=-0.45$; $\mathrm{p}<0.24)$.An assimilating effect can also be seen among the work fields with an increased IT background. The correlation between a successful assignment of icons $(>95 \%)$ and the work field is for the groups administration $(\mathrm{r}=0.92 ; \mathrm{p}<0.03)$ and natural science $(\mathrm{r}=0.89 ; \mathrm{p}<0.02)$ significant. A higher educational level correlates by trend with a higher number of correct assignments. However, this also, as the determined data for computer literacy, is not significant. Concluding, the decisive factor, while correctly assigning a symbols intent, is previous experience with computers. This result, within subjective computer literacy, is clearly influenced by the probands professional experience. Further, it may be said that educational levels do not generally have any correlation. Principally, there are no correlations between the investigated symbol classes and parameters. 
The probands preferences towards photos is cluster independent regarding the question, which symbol class possesses the highest recognizing reliability in a direct comparison.

Table 3

Distribution of correctly recognized [+], unassigned [/] and incorrectly recognized icons [-] in \%

\begin{tabular}{|c|c|c|c|c|c|c|c|c|c|c|c|c|c|c|c|}
\hline $\begin{array}{l}\text { Symbol Class } \rightarrow \\
\text { Scenarios } \downarrow\end{array}$ & $\begin{array}{l}\text { Picto } \\
{[+][}\end{array}$ & ogra & & & ipar & & & & & & & & & ota & \\
\hline Fluid Intake & 100 & 0 & 0 & 96 & 4 & 0 & 94 & 4 & 2 & 100 & 0 & 0 & 97 & 2 & \\
\hline Body Weight & 90 & 6 & 4 & 93 & 7 & 0 & 95 & 5 & 0 & 98 & 1 & 1 & 94 & 5 & \\
\hline Wellness & 87 & 11 & 2 & 90 & 9 & 1 & 89 & 10 & 1 & 94 & 6 & 0 & 90 & 9 & \\
\hline ECG Measure & 94 & 0 & 6 & 100 & 0 & 0 & 76 & 13 & 11 & 85 & 11 & 4 & 89 & 11 & 1 \\
\hline Blood Pressure & 85 & 15 & 0 & 87 & 11 & 2 & 89 & 10 & 1 & 91 & 8 & 1 & 88 & 11 & 1 \\
\hline System on / off & 84 & 12 & 4 & 79 & 14 & 7 & 91 & 5 & 4 & 97 & 3 & 0 & 88 & 8 & 4 \\
\hline Emerge & 85 & 12 & 3 & 84 & 13 & 3 & 86 & 6 & 8 & 84 & 8 & 8 & 85 & 10 & \\
\hline Activity & 74 & 13 & 13 & 83 & 13 & 4 & 87 & 9 & 4 & 92 & 0 & 2 & 84 & 10 & 0 \\
\hline Stop Alarm & 88 & 9 & 3 & 86 & 10 & 4 & 84 & 7 & 9 & 79 & 14 & 7 & 84 & 10 & 6 \\
\hline Medication & 67 & 26 & 7 & 88 & 4 & 8 & 89 & 3 & 8 & 92 & 5 & 4 & 84 & 9 & 7 \\
\hline Authentication & 72 & 22 & 6 & 80 & 19 & 1 & 79 & 11 & 10 & 87 & 11 & 2 & 79 & 16 & 5 \\
\hline Help /F.A.Q. & 63 & 24 & 13 & 80 & 12 & 8 & 84 & 7 & 9 & 85 & 10 & 5 & 78 & 14 & 8 \\
\hline Undo & 63 & 26 & 11 & 65 & 30 & 5 & 73 & 21 & 6 & 94 & 5 & 1 & 74 & 20 & 6 \\
\hline Home Screen & 42 & 25 & 33 & 50 & 10 & 40 & 74 & 8 & 18 & 83 & 10 & 7 & 62 & 13 & 25 \\
\hline & 78 & 14 & 8 & 83 & 11 & 0 & 85 & 9 & 6 & 90 & & & & & \\
\hline
\end{tabular}

\section{Conclusion}

The importance of telemedicine for present and future medical care with regard to demographic change is undisputed. However, due to a lack of specifications for elderly users, today's systems do not adequately recognize requirements from elderly users. The results of this user study enable design suggestions for a visualization of icons considering the abilities and preferences of elderly people. The investigation was carried out using hard copies of all icons. This was done in order to accumulate the biggest possible control sample and the most objective and reliable recommendations for the target group. This approach reduces ergonomic parameters as native resolution, contrast, luminance spread and intensity of varying display technologies, which may not be fully integrated into the study and would have had a direct influence on the results.

The feedback from experiment probands on their experiences shows that success and sustainability of medical technology is strongly dependant on overcoming individual user barriers and the integration of medical technology in a home environment without stigmatizing. So far, no systematic integration of user perspectives and preferences of older users in the product development process exists, making it difficult to establish medical assistance technology. The utilization allows not only the quality of life of older people to increase significantly but is also strategically important for many companies entering the "senior market". In this study carried out surveys represent fundamental research in order to adequately design age-adapted systems, which respect the requirements and living conditions of the ordinary "best-ager", not least generating a positive stand towards technology.

\section{Acknowledgment}

This research is funded by the German Federal Ministry of Education and Research BMBF (01FG10004) and the body responsible for the project is DLR.

\section{References}

[1] Mertens, A.; Przybysz, P.; Kausch, B.; Dünnebacke, D.; Schlick, C. (2009). Adequate assistance for elderly people in Homely Rehab. In Proceedings of intelligent interactive assistance and mobile multimedia computing conference 2009, Communication in Computer and Information Science (CCIS). Berlin: Springer.

[2] VDI/VDE (2006). Ambient Assisted Living - European Overview Report: Europe Is Facing a Demographic Challenge: Ambient Assisted Living Offers Solutions.

[3] Ijsselsteijn, W.; Nap, H.; de Kort, Y.; Poels, K.( 2007). Digital game design for elderly users. In Proceedings of the 2007 Conference on Future Play Future Play '07. ACM, New York, NY, 17-22.

[4] Dreyfuss, H. (1972). Symbol Resources. New York: McGramHill.

[5] Mertens, A.; Dünnebacke, D.; Kausch, B.; Laing, P.; Schlick, C. M. (2009). Innovation of homely rehab with help of telemedical services. In IFMBE Proceedings of World Congress on Medical Physics and Biomedical Engineering; Dössel, Schlegel (Hrsg.), Munich, Springer.

[6] Horton, W. (1994). Das ICON-Buch: Entwurf und Gestaltung visueller Symbole und Zeichen. Bonn: Addison-Wesley.

[7] Weidenbeck, S. (1999). The use of icons and labels in an end user application program: An empirical study of learning and retention. In Behavior and Information Technology 18 (2), 6882.

[8] Kacmar, P.; Carey, J.M. (1991). Assessing the usability of icons in user interfaces. Behavior and Information Technology 10 (6). 443-457.

[9] Lodding, K. (1983). Iconic interfacing. In IEEE Computer Graphics and Applications 4 (12), 13-23.

[10]Wickens, C.D. (1992). Engineering Psychology and Human Performance. New York: HarperCollins.

[11] Gaver, W.W. (1991). Technology affordances. In Conference on Human Factors in Computer Systems. New Orleans: Addison-Wesley, 79-84. 
[12] Waterworth, J.A. (1993). Form icons to interface models: designing hypermedia from the bottom up. In International Journal of Man-Machine Studies 39 (3), 453-472.

[13] Gittins, D. (1986). Icon-based human-computer interaction. In International Journal of Man-Machine Studies 24 (6), 519543.

[14] Wilhelm, H. (1998). Erfahrungen mit dem Einsatz anwendungsspezifischer Piktogramme zur partizipativen Anforderungsanalyse. In Informatik - Forschung und Entwicklung (13), 217-226.

[15] Guastello, S.; Traut, M.; Korienek, G. (1989) Verbal versus pictorial representations of objects in a human-computer interface. In International Journal of Man-Machine Studies 31 (1), 99-120.

[16] Ma, X.; Cook, P.R. (2009). How Well do Visual verbs Work in Daily Communication for Young and Old Adults? In Proceedings of CHI 2009 - Accessibility/Special Needs.

[17] Guastello, S.J.; Traut, M.; Korienek, G. (1989). Verbal versus pictorial representations of objects in a human-computer interface. In International Journal of Man-Machine Studies, Volume 31 (1), 99-120.

[18] Schneider, N.; Stöcker, S.; Grandt, M.; Schlick, C. (2006). Altersdifferenzierte Adaption der Mensch-RechnerSchnittstelle, In Zeitschrift für Arbeitswissenschaft 60 (3), 171-180.

[19] Arnott, J.L.; Khairulla, Z.; Dickinson, A.; Syme, A.; Alm, N. (2004). E-mail Interfaces for Older People. In IEEE International Conference on Systems, Man and Cybernetics, 111-117.
[20]Ziefle, M.; Bay, S. (2004). Mental models of Cellular Phones Menu. Comparing older and younger novice users, Mobile Human Computer Interaction. Berlin, Heidelberg: Springer, 25-37.

[21] Schroeder, S.; Ziefle, M. (2008). Effects of Icon Concreteness and Complexity on Semantic Transparency: Younger vs. Older Users. In Proceedings of the 11th international conference on Computers Helping People with Special Needs (ICCHP '08), Miesenberger, K.; Klaus, J.; Zagler, W.; Karshmer, A. (Eds.). Berlin, Heidelberg: Springer, 90-97.

[22]Kim, J.H.; Lee, K.P. (2005). Cultural difference and mobile phone interface design: icon recognition according to level of abstraction. In Proceedings of the 7th international Conference on Human Computer interaction with Mobile Devices \& Services New York, NY, 307-310.

[23]Lindberg, T.; Nasanen, R. (2003).The effect of icon spacing and size on the speed of icon processing in the human visual system. In Displays 24 (3) 111-120.

[24]Beier, G. (2004). Kontrollüberzeugungen im Umgang mit Technik: Ein Persönlichkeitsmerkmal mit Relevanz für die Gestaltung technischer Systeme. Dissertation. Berlin.

[25] Sengpiel, M.; Struve, D.; Dittberner, D.; Wandke, H. (2008) Entwicklung von Trainingsprogrammen für ältere Benutzer von IT-Systemen unter Berücksichtigung des Computerwissens. In Wirtschaftspsychologie, Alter und Arbeit 3 (2008), 94-105.

[26]Ferris, F.L. 3rd; Kassoff, A.; Bresnick, G.H. (1982) New visual acuity charts for clinical research. In Journal of Ophthalmology 94:91-96.

[27]Ishihara, S. (1998). Ishihara's Test for Colour Deficiency Concise Edition. Tokyo: Kanehara \& Co., LTD. 